\title{
The Joint Influence of Intra- and Inter-Team Learning Processes on Team Performance: A Constructive or Destructive Combination?
}

\author{
Rike Bron $^{1}$ (D) Maaike D. Endedijk ${ }^{1}$. \\ Ruth van Veelen ${ }^{2} \cdot$ Bernard P. Veldkamp $^{3}$
}

Received: 16 March 2017 / Accepted: 8 January 2018 /

Published online: 1 February 2018

(C) The Author(s) 2018. This article is an open access publication

\begin{abstract}
In order for teams to build a shared conception of their task, team learning is crucial. Benefits of intra-team learning have been demonstrated in numerous studies. However, teams do not operate in a vacuum, and interact with their environment to execute their tasks. Our knowledge of the added value of inter-team learning (team learning with external parties) is limited. Do both types of team learning compete over limited resources, or do they form a synergistic combination? We aim to shed light on the interplay between intra- and inter-team learning in relation to team performance, by including adaptive and transformative sub-processes of intra-team learning. A quantitative field study was conducted among 108 university teacher teams. The joint influence of intra- and inter-team learning as well as structural (task interdependence) and cultural (team efficacy) team characteristics on self-perceived and externally rated team performance were explored in a path model. The results showed that adaptive intra-team learning positively influenced self-perceived team performance, while transformative intra-team learning positively influenced externally rated team performance. Moreover, intra-team and inter-team learning were found to be both a constructive and a destructive combination. Adaptive intra-team learning combined with inter-team learning led to increased team performance, while transformative intra-team learning combined with inter-team learning hurt team performance. The findings demonstrate the importance of distinguishing between both the scope (intra- vs. inter-team) and the level (adaptive vs. transformative) of team learning in understanding team performance.
\end{abstract}

Rike Bron

r.bron@utwente.nl

1 Department of Educational Sciences, University of Twente, Enschede, The Netherlands

2 Department of Social, Health, and Organisational Psychology, Utrecht University, Utrecht, The Netherlands

3 Department of Research Methodology, Measurement and Data Analysis, University of Twente, Enschede, The Netherlands 
Keywords Intra-team learning - Inter-team learning - Adaptive learning - Transformative learning $\cdot$ Team performance $\cdot$ Structural equation modelling $($ SEM)

Teamwork has become a self-evident aspect of work in organizations (Kozlowski and Ilgen 2006). By means of team learning, teams build a shared conception of their tasks and how to execute them, which is crucial for team performance: the degree to which teams reach or transcend their goals (Antoni and Hertel 2009; Van den Bossche et al. 2011). The first models on team learning mainly focussed on learning processes within the team (Edmondson 1999). While the importance of teams' external environment has been stressed in theoretical models (Decuyper et al. 2010; Kozlowski and Bell 2013), to date, empirical studies investigating both intra-team learning and inter-team learning simultaneously are scarce. As a result, insight in how inter-team learning and intrateam learning mutually influence team performance is still lacking, with some studies pointing to an added value of inter-team learning (Bresman 2010), while others demonstrate that inter-team learning forms an interference to team performance (Wong 2004). In the current study, we take an interactive approach and study how intra-team learning and inter-team learning may complement or compete over each other in their contribution to team performance.

Team learning has been studied in a variety of professional contexts, for example among medical staff in healthcare (Timmermans et al. 2012), military teams (Veestraeten et al. 2013) and student teams (Van den Bossche et al. 2011). Recently, universities have also started to develop towards team-based working among academic teaching staff (Akbari et al. 2016; Gast et al. 2017). Traditionally, teaching at a university has been a highly individual and autonomous job (Van der Rijst 2009). Yet, demands from society require teachers to integrate their efforts to design multidisciplinary courses that provide students with a wide range of skills and knowledge (Scott 2000). The current study focuses on a university that had just initiated such an educational reform for all undergraduate study programs. The reform entailed a shift towards a more student-centred and project-based curriculum, which intends students to become 'T-shaped professionals': experts in their discipline, but at the same time capable of applying their knowledge in a broader context, in collaboration with other disciplines and with society (Barile et al. 2012). In order to accomplish this, multidisciplinary teacher teams were formed to design new and larger courses, consisting of one central theme, with multiple content components and a joint project. In other words, the team members were interdependent both on each other to design an innovative joint product and on other teams and external parties to align their design with the designs of other teams. As a result, we found this context highly suitable for gaining first insights in the intra- and inter-team learning processes of university teachers.

Thus, the aim of the current study is to examine the interactive effect of intra-team learning and inter-team learning on team performance in university teacher teams. We will work from an input-process-output (IPO) framework to provide insight in both antecedents (input) and consequences (output) of team learning (Kozlowski 2015). With regards to the antecedents, we will focus on task interdependence and team efficacy, as both have been proven to be crucial input factors to team learning processes (Bresman and Zellmer-Bruhn 2013; Van den Bossche et al. 2006). With regards to consequences of team learning, we focus on multiple measures of team performance as output factors. 


\section{Theoretical Framework}

Team learning can be defined as a compilation of processes by which a team builds and maintains a shared conception of their tasks (Van den Bossche et al. 2006). Traditionally, team learning has solely been studied as a within-team phenomenon (Wilson et al. 2007). Properties of a teams' external environment have only been studied as input factors for team learning (Antoni and Hertel 2009). In most working contexts, however, teams do not work in isolation; rather they are part of a larger system in which they focus on different tasks in different collaborative settings (Engeström et al. 1995). Apart from collaborating in their specific team, the university teachers in our study are part of different research departments, and are a vital part of the broader study program for which they design and teach their course. As teams need to create alignment with this external environment (Bresman and Zellmer-Bruhn 2013), their interactions with external parties (other institutions, teams, or persons within the organizational context) can be seen as an essential part of the team learning process itself (Zellmer-Bruhn 2003). Specifically, in our study context teachers need to build a shared conception within their (interdisciplinary) teaching team of the joint course they are designing, but their opinion about this design will be shaped by discussions with other teams about their experiences with, for example, certain assessment methods. We therefore distinguish between the within-team interactional learning processes called intra-team learning, and the learning processes between teams and external parties called inter-team learning. We will investigate the interactive effect of intra- and inter-team learning in order to gain insight in whether inter-team learning strengthens or weakens the facilitating effect of intra-team learning on performance.

\section{Intra-Team Learning}

Following Van den Bossche et al. (2011), we adopt an interactional approach to team learning, in which team-level understanding and agreement should be reached through social interaction. This approach stresses that team learning emerges between individuals, rather than within individuals, and fits the notion that teams can come to ideas and solutions that go beyond the sum of the individual team members' activities and capacities (Paavola and Hakkarainen 2005; Van den Bossche et al. 2011). The goal of team learning is to build a shared conception about the 'problem' (in the case of university teaching, a course that needs to be designed and taught) and how to tackle it, upon which team members can base their subsequent individual and collaborative work (Akkerman et al. 2007; Van den Bossche et al. 2011). As such, "individual initiative serves the communal effort to create something new" (Paavola and Hakkarainen 2005, p. 546).

The type of task for the teams in our study can be qualified as complex and innovative, given that the end product should be a new course consisting of a coherent whole of different content components. Designing an innovative product requires processes of recognizing, sharing and refining existing good practices, as well as processes in which new ideas are developed. In order to do justice to the specific types of team learning required by the complex and innovative task in the current study, we differentiate between sub dimensions of intra-team learning. Various distinctions in specific team learning processes have been identified in previous studies, such as sharing, co-construction, constructive conflict (Van den Bossche et al. 2011), reflection 
and action (Edmondson 1999), task, process and social learning (Jehn and Rupert 2008). We borrow from this rich knowledge base, yet in order to maintain conceptual clarity and parsimony in our use of terminology, we differentiate between two different 'levels' of intra-team learning that broadly encompass elements of sub dimensions in prior literature, and rely on the terminology adaptive versus transformative learning.

Adaptive learning involves making small adjustments to existing knowledge and refining existing solutions (Ellström 2001; Kostopoulos and Bozionelos 2011; Sessa et al. 2011). It implies to maintain a certain status quo, but at the same time to adapt to contextual and task demands, which requires teams to learn to make minor changes in their behaviour (Silberstang and London 2009). Engaging in adaptive learning is relatively easy and requires little cognitive effort, as it does not challenge team members' underlying beliefs and assumptions. In team interaction, adaptive intrateam learning manifests itself by team members' knowledge sharing (KoeslagKreunen et al. 2017; Van den Bossche et al. 2006): knowledge that is already present in the mind of one of the team members is communicated to the others and accepted as shared knowledge. As a result, the outcome of adaptive learning is an accumulation of compatible pieces of shared knowledge in the team's collective knowledge repository. For example, in the context of university teacher teams, adaptive intra-team learning could be one teacher explaining or demonstrating an activating type of lecture style that he/she will use during the course. Sharing this information allows other team members to coordinate their actions accordingly (Van den Bossche et al. 2011), and thereby maintaining coherence in the course.

Adaptive learning can evolve into transformative intra-team learning when team members start building further on, or argue against, the introduced knowledge (Van den Bossche et al. 2011). Transformative intra-team learning involves creating new knowledge through integration of different perspectives and ideas on a collective level, not yet present in the minds of the individual team members (Ellström 2001; Kerosuo and Engeström 2003; Sessa et al. 2011). With transformative learning, a current or known strategy is abandoned and replaced by a different or new approach (Silberstang and London 2009). As such, this level of learning is necessary when teams face a complex and innovative task which they cannot execute solely based on their previous experiences (Ellström 2001). Collaborative course design is a typical example of such a task, and requires teacher teams to build further on their existing (individual) experiences and ideas. Transformative intra-team learning can occur through two different processes. On the one hand, transformative intra-team learning can take place in the form of integrating matching pieces of knowledge towards something new, by building on, refining, and modifying existing (shared) knowledge in adaptive learning processes (Decuyper et al. 2010). On the other hand, transformative intra-team learning can also take a more conflicting form, such that teams argue over a divergence in viewpoints or opinions and work towards a new shared solution. In both cases, transformative forms of team learning require higher levels of cognitive effort (Sessa et al. 2011). For example, referring back to the previous example, when members in university teacher teams do not agree with a proposed activating lecture type, this requires team members to be able to hold a critical attitude towards each other's knowledge and ideas, and actively and openly discuss mutually distinct viewpoints. Eventually, such discussion should lead to a new and integrated perspective on how to teach lectures (Kasl et al. 1997; Van den Bossche et al. 2006). 
Taken together, based on prior team learning models (Ellström 2001; Sessa et al. 2011; Van den Bossche et al. 2011), intra-team learning consists of different levels of learning, the most important of which the lower-order adaptive team learning process and higher-order transformative team learning process. Both levels of intra-team learning are necessary in the context of university teachers, where on the one hand, teams can proceed from their teaching expertise and experiences, but on the other hand, they are designing a complex and new type of course.

The Influence of Intra-Team Learning on Team Performance Team performance can be defined as: "the degree that team output meets or exceeds the performance standards given by supervisors or customers [in the case of university teacher teams: students] within or outside the organization" (Antoni and Hertel 2009, p. 255). Prior literature provided substantial empirical evidence for the positive impact of intra-team learning on team performance (Turner et al. 2014). For example, Van den Bossche et al. (2006) and Schippers et al. (2013) demonstrated a positive link between intra-team learning and team performance in a study among student groups. Similar findings were shown in the context of medical care (Ortega et al. 2014) and in teacher teams in vocational education (Wijnia et al. 2016). Importantly, however, these studies did not distinguish between adaptive and transformative forms of team learning.

Regarding adaptive intra-team learning specifically, a recent meta-analysis of 72 studies yielded a substantial positive effect of knowledge sharing activities within teams on team performance (Mesmer-Magnus and DeChurch 2009). Moreover, in an empirical study among students, intra-team knowledge sharing also positively influenced team performance (Van den Bossche et al. 2011). Together, this empirical work suggests a positive effect of the adaptive intra-team learning process on team performance. Regarding transformative intra-team learning, empirical evidence for a positive effect on team performance is more ambiguous. Though conflicting discussions in teams are generally negatively related to team performance (De Dreu and Weingart 2003; De Wit et al. 2012), effects have shown to be predominantly positive when such critical discussions were constructive, and with the intention to work towards mutual agreement, (Stalmeijer et al. 2007; Van den Bossche et al. 2011).

Taken together, while the empirical knowledge base for a positive effect of adaptive intra-team learning on team performance is well-established, the empirical evidence for a positive effect for transformative intra-team learning on performance is still scarce. While transformative intra-team learning is likely to lead to higher team performance, particularly in the context of complex and innovative team products such as a new and interdisciplinary course curriculum, more research is needed to establish its added value in relation to more adaptive forms of learning (Decuyper et al. 2010; Hülsheger et al. 2009; Kasl et al. 1997). In our study, we investigate both adaptive and transformative learning and expect it to have a positive effect on team performance in the university teacher teams (Hypothesis 1).

\section{The Complementing or Competing Role of Inter-Team Learning}

In most empirical studies to date, inter-team learning is studied as part of the broader concept of boundary crossing: a team's interaction with external parties in general 
(Marrone 2010). Boundary crossing can have non-learning related purposes, such as acquiring financial resources (Ancona and Caldwell 1992), but also learning-related purposes such as obtaining task-relevant knowledge or feedback (Bresman 2010). In the current study, we focus on the 'learning-related' part of boundary crossing and conceptualize this process as inter-team learning. In a multi-team system like our university teaching context, it is likely that inter-team learning will occur between interconnected teams. However, inter-team learning also refers to the learning-related interactions of teams with other external parties, such as programme directors or students. Moreover, inter-team learning can even go beyond the borders of the institution and profession (Kerosuo and Engeström 2003), for example when academics reach out to their international peer network for teaching input and materials. Inter-team learning contributes to team performance via identification of task-relevant external knowledge, translating the knowledge to the own team context, and embedding it in the teams' practices (Akkerman and Bakker 2011; Bresman 2013). In this study, we therefore investigate inter-team learning as a moderator in the relationship between intra-team learning and performance with the aim to shed more light on the question whether inter-team learning complements or competes the expected positive relationship between intra-team learning and performance.

Theoretically, we can argue for both a competitive and a complementing combination of intra- and inter-team learning. On the one hand, intra- and inter-team learning compete over the limited resources a team has (Choi 2002), such that spending more time on inter-team learning reduces the effort a team can make for intra-team learning. Moreover, gathering task-relevant external information can lead to fragmentation of knowledge within the team (Engeström et al. 1995), which may result in an 'information overload'. In this situation, it is very difficult to come to within-team consensus and reach decisions (Ancona and Caldwell 1992; Van Woerkom and Croon 2009). On the other hand, engagement in both intra- and inter-team learning may also positively reinforce team performance (Choi 2002). For example, inter-team learning provides team members with inspiring ideas that may positively contribute to constructive intrateam discussions. Engaging in inter-team learning provides a team with a greater diversity in knowledge, and as such may help to overcome inertia and groupthink (Engeström et al. 1995) and may facilitate to "learn in the 'right' direction" (Decuyper et al. 2010, p. 117).

There is a growing amount of empirical work on the direct effect of inter-team learning on team performance (e.g. Chan et al. 2003; Van Woerkom and Croon 2009), and overall, prior research has evidenced that engaging in inter-team learning "is a crucial element in fostering innovation in the workplace" (Hülsheger et al. 2009, p. 1139). Research on the interactive effect of intra- and inter-team learning, however, is scarce. To our knowledge, only Wong (2004) and Bresman (2010) have empirically investigated the interactive effect of intra- and inter-team learning on team performance. Wong's (2004) study took place in 78 teams in four different types of firms. The results showed that engaging in inter-team learning impeded the positive contribution of intra-team learning to team efficiency. This finding supports the competitive interplay of intra- and inter-team learning, such that inter-team learning disrupts the flow from intra-team learning to team performance. Bresman (2010) conducted a study in 62 teams in a pharmaceutical firm and distinguished between inter-team learning with two different types of external parties: external collaborative stakeholders that could share 
advice and lessons with the team, and external competitors from which the team could 'steal' ideas and information. The results showed a positive interaction effect of intrateam learning and inter-team learning with collaborative stakeholders, indicating that the lessons learned from these stakeholders enforced the positive effect of intra-team learning on team performance. This finding supports the synergistic relationship of intra- and inter-team learning with team performance. For inter-team learning with the latter group of stakeholders, no interaction effect was found (Bresman 2010).

Taken together, these studies lead us to assume that inter-team learning moderates the relationship between intra-team learning and team performance. According to Bresman (2013), the direction of the interaction effect is likely to depend on the task environment in which a team is situated. If a focus on quality is dominant in the task environment (such as in his 2010 study), a constructive combination of intra- and interteam learning can be expected. If efficiency is the dominant aspect of the task environment (such as in the study of Wong 2004), the combination of intra- and inter-team learning is likely to be deconstructive. The task of the university teacher teams is to design an innovative joint product as part of an educational reform process. We therefore consider university teachers teams to be especially focused on the quality of their product (a high-quality course design), but at the same time striving for efficiency in their design process. Therefore, we expect that for teams engaging highly in inter-team learning, the (hypothesized positive) effect of intra-team learning on team performance is strengthened (Hypothesis 2).

\section{Structural and Cultural Influences on Team Learning}

Thus far, we have focussed on consequences of team learning and how team learning impacts on team performance. Building on the input-process-output (IPO) framework (Kozlowski 2015; LePine et al. 2008), in this final section we will focus on antecedents of team learning, or so-called input factors. Specifically, we focus on both a structural aspect of the team (i.e., the blueprint of the team's interactive network), namely task interdependence, and a cultural aspect of the team (i.e., norms and beliefs about the team), namely team efficacy, as important antecedents of team learning and performance.

Task Interdependence Task interdependence refers to the extent to which team members need information, materials, and support from each other, in order to carry out their tasks (Van der Vegt et al. 2003). Task interdependence has been shown to have a direct positive effect on team performance (Lemieux-Charles and McGuire 2006; LePine et al. 2008). Mutual interdependence forces teams to interact, because members have to ask for and provide each other with knowledge in order to be able to proceed with their own tasks (Van der Vegt et al. 2003). As intra-team learning emerges from interaction, task interdependence has been shown to be a main driver of intra-team learning (Decuyper et al. 2010; Knapp 2010; Van den Bossche et al. 2006). Given that teaching in higher education has long been a rather individualistic task (Gast et al. 2017), a feeling of task interdependence is not a given for university teaching teams. We thus expect teams that are able to create a shared sense of task interdependence to reach higher team performance, via intrateam learning (Hypothesis 3). 
Team Efficacy Team efficacy is the collective feeling of being able to successfully fulfil a task (Gully et al. 2002). As with self-efficacy, the importance of team efficacy in research on workplace learning stems from the notion that ability alone is not a guarantee for good performance. The belief in one's own capacities is necessary for a person to actually make use of his knowledge and skills (i.e. participate in team learning), which is crucial for performance (Bandura 1993). Similarly, in team research there appears to be unequivocal consensus that team efficacy positively affects intrateam learning and team performance (Gully et al. 2002; Knapp 2010; Kozlowski et al. 2013; Marrone et al. 2007). To this end, we expect that among university teacher teams too, higher team efficacy will lead to higher team performance via intra-team learning (Hypothesis 4).

\section{The Present Study}

With a growing need for teamwork in the university teaching context (Scott 2000), it is important to explore whether well-researched models concerning team learning (Decuyper et al. 2010; Van den Bossche et al. 2011) can be applied to university teacher teams. As such, our research goal is to test our hypothesized relationships (Fig. 1) in this specific context.

\section{Method}

\section{Participants and Procedure}

To empirically test proposed relationships in our research model (see Fig. 1) we conducted a cross-sectional survey study at a university in The Netherlands that had just initiated the previously described educational reform, which required teachers to collaborate in teams. Participants in the study were all members of teacher teams involved in the (re)design of the courses for the new curriculum of 19 different undergraduate study programs. Most teams had a series of meetings in which they discussed course design issues and in which team learning could take place. For each course, a teacher team was newly composed, and generally consisted of members from different departments, and in some cases even from different faculties (e.g. behavioural

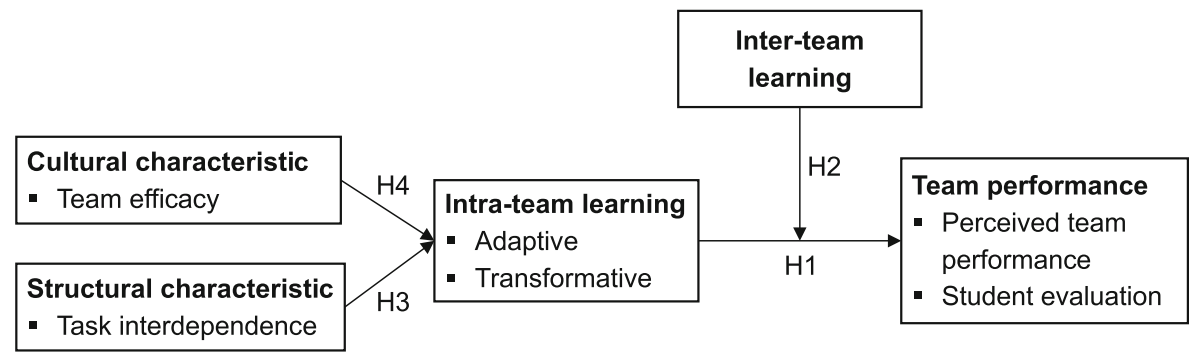

Fig. 1 Conceptual model 
sciences and engineering technology). While in each team one team member took on the role of coordinator, leadership roles were largely distributed among all team members, depending on their field of expertise. The role of the coordinator thus entailed mostly administrative tasks, such organizing team meetings and (during the course) collecting all student grades. The teams were either responsible for designing a course for first-year or second-year students. Data collection took place in the second and third year of the reform (2014-2015 and 2015-2016). At this point, teacher teams from the courses for first-year students were re-designing their courses after the evaluations of the first or second time. The teacher teams from the courses for second-year students were designing their course for the first or second time. As the reform had been piloted in one study program, there was one team redesigning its course for the fourth time.

All team coordinators $(N=138)$ were personally contacted in order to retrieve the contact details of the team members. Seven team coordinators refused to participate, these teams were left out of the study. In total, 689 teachers of 131 teams received the questionnaire and 460 people in 130 teams responded (response rate individual level: 67\%; team level: 99\%). We deleted incomplete individual responses and proceeded with 416 individuals in 128 teams. A subsequent total of 20 teams were omitted from analyses, as the coordinator indicated that they had never had a face-to-face team meeting and thus could not answer questions regarding interactive team learning behaviours. The final dataset consisted of 348 individuals in 108 teams $(68 \%$ male, $32 \%$ female; $\left.M_{\text {age }}=46.11, S D=10.42\right)$. Team size varied from 2 to 12 members $(M=$ 5.17, $S D=2.15)$. Regarding team tenure, the final sample included teams going through the design process for the first time (one year tenure, 49 teams), and teams going through a redesign process (second, third, or fourth-year tenure, 59 teams). At the end of the (re-)design process, two weeks before the start of the course, the questionnaire was sent to all team members via email, after which two reminders were sent. The study was in compliance with the university's ethical standards.

\section{Instruments}

A complete list of the final set of items for the variables included in the study can be found in Appendix 1.

Team Learning To measure intra-team learning, we used the team learning questionnaire of Van den Bossche et al. (2011). Because this questionnaire had not yet been used to explicitly distinguish between adaptive and transformative intra-team learning, we complemented it with items from other existing intra-team learning scales (De Groot et al. 2012; Van Offenbeek 2001; Visschers-Pleijers et al. 2005). To measure inter-team learning, we selected items from the distal learning scale of Wong (2004) and the external activities scales of Bresman (2010). If necessary, items were adapted to the study context.

We performed Exploratory Factor Analysis (EFA, oblique rotation) on intra- and inter-team learning scales based on principal axis factoring (Schmitt 2011) and followed the criteria for item retention from Worthington and Whittaker (2006). Results showed a three-factor solution, in which adaptive intra-team learning, transformative intra-team learning and inter-team learning were distinguished. Factor loading are provided in Appendix 2. Four items were removed because of cross-loadings. The 
three-factor solution from EFA was subsequently subjected to confirmatory factor analysis (CFA) using Satorra-Bentler chi-square correction (MLM estimator; Hox and Bechger 1998). Evaluation of fit indices was done using the criteria as summarized by Kyndt and Onghena (2014) $\left(\chi^{2} p\right.$-value $>.05, \mathrm{CFI} \geq .90, \mathrm{TLI} \geq .95, \mathrm{RMSEA} \leq .08$, SRMR $\leq .08)$. The CFA on the adaptive intra-team learning, transformative intra-team learning and inter-team learning scales retrieved an adequate fit $\left(\chi_{\text {SB }}^{2}(167)=370.957\right.$, $p<.001$; CFI $=.926$; TLI $=.916$; RMSEA $=.065$; SRMR $=.055)$. Reliability of the scales was good: adaptive intra-team learning $(\alpha=.85)$, transformative intra-team learning $(\alpha=.89)$, inter-team learning $(\alpha=.86)$.

Team Performance Team members' self-reported team performance was measured with 5 items based on scales adapted from Van Woerkom and Croon (2009) and Zellmer-Bruhn and Gibson (2006) and showed good reliability $(\alpha=.84)$. To measure externally rated performance, we relied on students' course evaluations based on a questionnaire, which is standard procedure at the institute under study. We used the mean score of six items from this questionnaire indicating student satisfaction with the course $(\alpha=.80)$. The items reflected aspects such as course coherence and quality of the teachers and the tests.

Structural and Cultural Influences To measure task interdependence, four items were used from Oude Groote Beverborg et al. (2015) and proved to be reliable $(\alpha=.85)$. To measure team efficacy, a five item scale was selected and adapted to our context (Moolenaar et al. 2012) and was reliable $(\alpha=.77)$.

Common Method Bias To investigate the possible presence of common method bias, we subjected all self-reported items to an unrotated exploratory principal component analysis (PCA), constraining the number of factors to one. When the single factor explains the majority of the variance ( $>50 \%$ ), common method bias is assumed to be present (Podsakoff et al. 2003). The single factor in our PCA explained $34 \%$ of variance. Similarly, we conducted a CFA hypothesizing that all items loaded on one factor (Podsakoff et al. 2003). Following the criteria of Kyndt and Onghena (2014), we found a bad fit for the one-factor model $\left(\chi_{\mathrm{SB}}^{2}(741)=6111.643, p<.001\right.$; CFI = .624; $\mathrm{TLI}=.603$; RMSEA =.104; SRMR =.098). Therefore, we do not expect common method bias to influence the results.

\section{Analytical Strategy}

Analyses were conducted at the team level because both the hypotheses and the measures were formulated at the team level. We calculated interrater agreement $\left(r_{\mathrm{WG}(\mathrm{J})}\right)$ and average deviation (AD) to justify aggregation of the individual data to the team level. ICC values were not taken into account as they tend to be very low for small team sizes, which was the case in our sample (Bliese 2000). All values can be found in Table 1. For a 5-point scale, a mean $\mathrm{AD}<.80$ is acceptable (LeBreton and Senter 2007), which was the case for all of our scales. The conventional cut-off point for justifying aggregation based on $r_{\mathrm{WG}}$ is .70 (LeBreton and Senter 2007), all scales complied with that rule. Taken together, we considered aggregation justified. 
Table 1 Interrater agreement, average deviation, means, standard deviations and correlations of the measured variables

\begin{tabular}{|c|c|c|c|c|c|c|c|c|c|c|c|c|}
\hline Variables & $r_{W G(J)}$ & $A D$ & $M$ & $S D$ & 1 & 2 & 3 & 4 & 5 & 6 & 7 & 8 \\
\hline \multicolumn{13}{|l|}{ Influencing factors } \\
\hline 1. Team efficacy & .88 & .51 & 3.94 & .36 & & & & & & & & \\
\hline 2. Task interdependence & .84 & .50 & 4.05 & .48 & $.47^{*}$ & & & & & & & \\
\hline \multicolumn{13}{|l|}{ Intra-team learning } \\
\hline 3. Adaptive learning & .86 & .53 & 3.87 & .51 & $.50^{*}$ & $.50^{*}$ & & & & & & \\
\hline 4. Transformative learning & .90 & .52 & 3.63 & .44 & $.55^{*}$ & $.49^{*}$ & $.69^{* *}$ & & & & & \\
\hline \multicolumn{13}{|l|}{ Inter-team learning } \\
\hline 5. Inter-team learning & .81 & .67 & 3.15 & .56 & $.31 *$ & .10 & $.32^{* *}$ & $.39 *$ & & & & \\
\hline \multicolumn{13}{|l|}{ Team effectiveness } \\
\hline 6. Team performance & .90 & .50 & 3.87 & .44 & $.74 *$ & $.36^{*}$ & $.56^{* *}$ & $.43^{*}$ & $.27 *$ & & & \\
\hline 7. Student evaluation & & & 3.43 & .42 & .00 & -.02 & .07 & .15 & -.05 & .02 & & \\
\hline \multicolumn{13}{|l|}{ Covariates } \\
\hline 8. Team size & & & 5.19 & 2.15 & -.18 & -.07 & -.17 & -.08 & -.18 & $-.25^{*}$ & -.07 & \\
\hline 9. Team tenure & & & & & -.05 & $-.24 *$ & -.09 & .07 & .03 & .16 & .07 & .09 \\
\hline
\end{tabular}

$* p<.05, * * p<.01$

In order to do justice to the high complexity of team learning, we tested the complete conceptual path model (Fig. 1) at once (Hayes et al. 2017; Pek and Hoyle 2016). We conducted structural equation modelling (SEM), which is increasingly used for testing complex models including indirect effects (Pek and Hoyle 2016, p. 159). We used the Lavaan package in R (Rosseel 2012), and applied the Satorra-Bentler chi-square correction (Hu and Bentler 1999). ${ }^{1}$ Causal paths were drawn from the structural and cultural input variables to all intra-team learning and team outcome variables. Also, paths were drawn from all team learning variables to team outcome variables. Moreover, adaptive intra-team learning and transformative intra-team learning were allowed to correlate as both were part of the overarching concept of intra-team learning. Before calculating and entering the interaction terms, we centred all team learning variables (Kline 2011). Finally, team size and team tenure were included as covariates. Evaluation of fit indices was done using the earlier mentioned criteria as summarized by Kyndt and Onghena (2014).

\section{Results}

\section{Descriptives}

The means and correlations of the model variables are provided in Table 1. All team learning processes were positively correlated with each other, indicating that sub elements of team learning processes are generally positively associated with each other.

\footnotetext{
${ }^{1}$ Additionally, bias-corrected bootstrapping was performed to test the significance of the indirect effects (MacKinnon et al. 2004; Nevitt and Hancock 2001). We checked whether the confidence interval did not include zero, and only report results that comply with this rule.
} 


\section{Model Fit}

The structural path model (Fig. 1) was a good fit to the data $\left(\chi_{\mathrm{SB}}^{2}(21)=24.002\right.$, $p=.293 ; \mathrm{CFI}=.981 ; \mathrm{TLI}=.960 ; \mathrm{RMSEA}=.046 ; \mathrm{SRMR}=.071)$. Standardized path coefficients of the significant paths are shown in Fig. 2. Results of this model showed that intra- and inter-team learning, together with structural and cultural influences, explained $62 \%$ of the variance in in perceived team performance and $14 \%$ of the variance in student evaluation. Of the covariates, team tenure was positively $(r=.38$, $p<.01)$ correlated with perceived team performance. Next to that, adaptive and transformative intra-team learning were positively correlated $(r=.52, p<.01)$.

\section{Hypothesis Testing}

In Hypothesis 1, we predicted a positive effect of adaptive and transformative intrateam learning on team performance. Our results were in line with this hypothesis, but provided a more fine-grained picture: for perceived team performance, a positive effect of adaptive intra-team learning was found $(\beta=.38, p<.01)$, while for student evaluation, a positive effect of transformative intra-team learning was found $(\beta=.31$, $p<.05)$. This indicates that teams that engaged more in adaptive intra-team learning scored higher on perceived team performance, while teams that engaged more in transformative intra-team learning obtained higher scores from the student's evaluations.

In Hypothesis 2, we predicted that inter-team learning would moderate the relationship between intra-team learning and team performance. We found two significant interaction effects of intra- and inter-team learning on student evaluation. First, we found an interaction effect of adaptive intra-team learning and inter-team learning on student evaluation $(\beta=.37, p<.05)$. Specifically, in teams that engaged highly in interteam learning, adaptive intra-team learning positively affected student evaluation scores, while in teams that engaged very little in inter-team learning, adaptive intrateam learning negatively affected student's evaluation scores (Fig. 3). From a different viewpoint, the interaction effect demonstrated that when teams did not engage in adaptive team-learning (or very little), high inter-team learning was in fact detrimental for externally rated team performance. Second, we found an interaction effect of transformative intra-team learning and inter-team learning on student evaluation $(\beta=-.33, p<.05)$. Specifically, for teams that engaged highly in transformative intra-

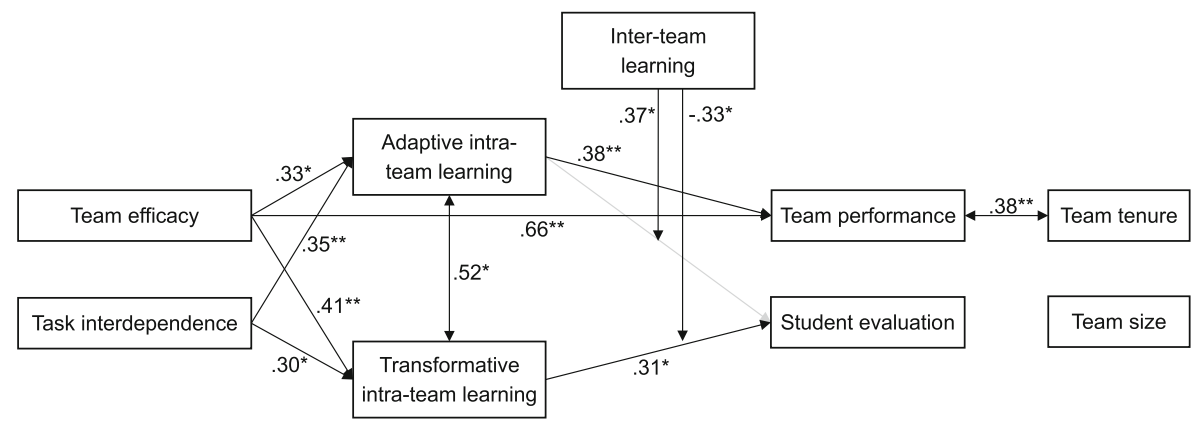

Fig. 2 Path model results, only significant paths are shown $(* p<.05$, ** $p<.01)$ 


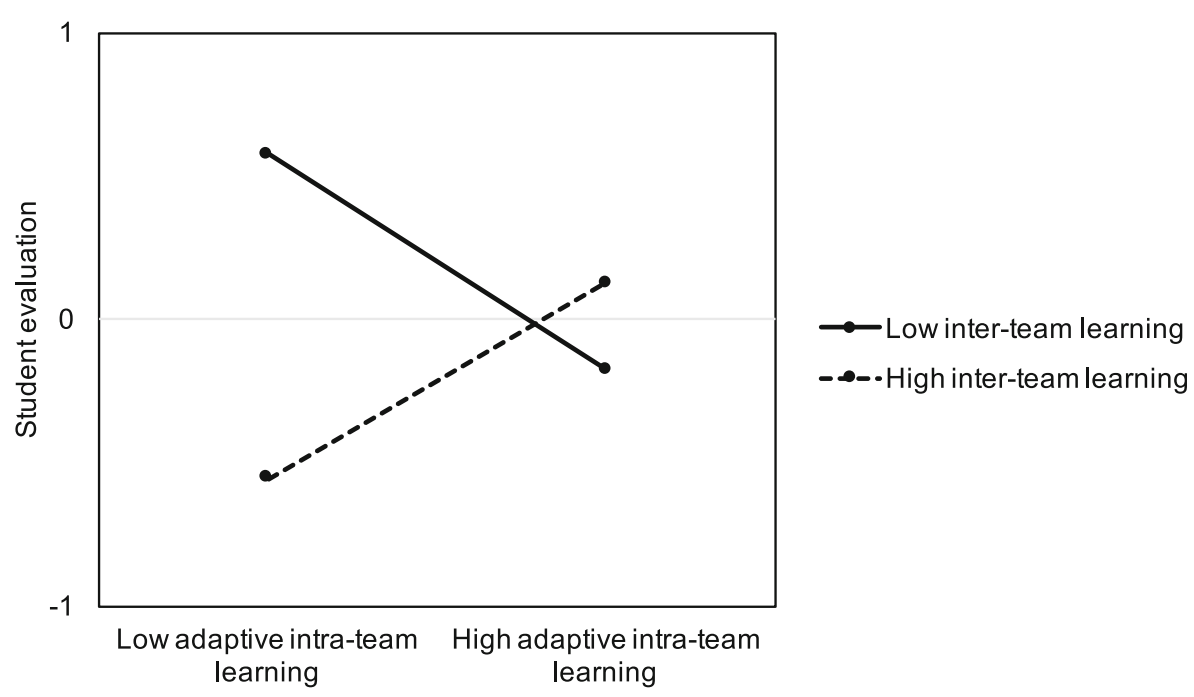

Fig. 3 Interaction effect of adaptive intra-team learning and inter-team learning on student-rated team performance

team learning, engaging more in inter-team learning yielded lower student evaluation scores (Fig. 4). On the other hand, the interaction plot showed that when teams engaged little in transformative intra-team learning, engaging in inter-team learning neither increased nor decreased student evaluation scores (Fig. 4). So, interestingly, even though the direct relationship between transformative intra-team learning and student evaluation was positive, this relationship was impeded when teams also engaged highly in interteam learning. We found no significant interaction effects on perceived team performance. Thus, Hypothesis 2 was partially confirmed.

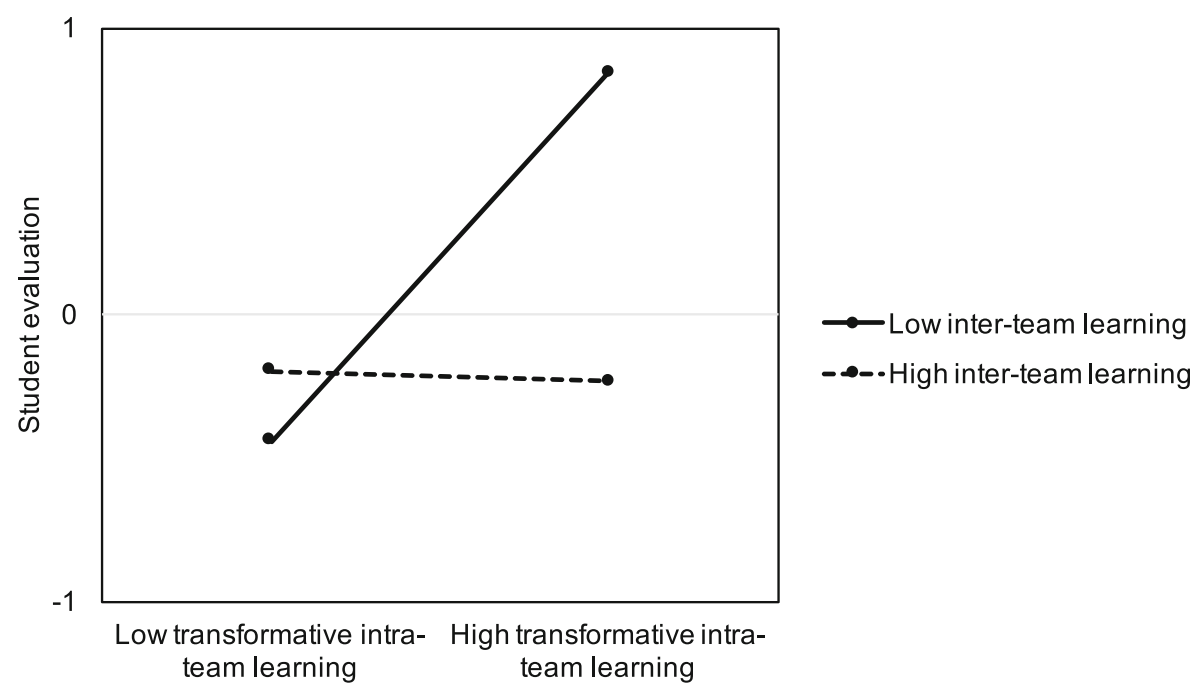

Fig. 4 Interaction effect of transformative intra-team learning and inter-team learning on studentrated team performance 
In Hypothesis 3, we predicted that task interdependence would positively affect team performance via intra-team learning. We found positive direct effects of task interdependence on both adaptive $(\beta=.35, p<.01)$ and transformative $(\beta=.30, p<.05)$ intra-team learning, indicating highly interdependent teams engaged more in intra-team learning than low interdependent teams. We performed additional indirect effects testing to test the mediating role of intrateam learning in the relationship between task interdependence and team performance (Table 2). The results indicated that adaptive intra-team learning positively mediated the relationship between task interdependence and perceived team performance $(\beta=.13, p<.05)$, such that task interdependence positively affected adaptive intra-team learning, which positively affected perceived team performance. We found no evidence for transformative intra-team learning as a mediator between task interdependence and student evaluation. Only the relationship between task interdependence and perceived team performance was thus mediated by only adaptive intra-team learning.

In Hypothesis 4, we predicted that team efficacy would positively affect team performance via intra-team learning. We found positive direct effects of team efficacy on both adaptive $(\beta=.33, p<.05)$ and transformative $(\beta=.35$, $p<.01)$ intra-team learning, indicating that high efficacious teams engaged more in intra-team learning than low efficacious teams. Team efficacy also positively influenced perceived team performance $(\beta=.66, p<.01)$, indicating that higher efficacious teams scored higher on perceived team performance. The results from additional indirect effects testing (Table 2) indicated that adaptive intra-team learning positively mediated the relationship between team efficacy and perceived team performance $(\beta=.13, p<.01)$, such that team efficacy positively affected adaptive intra-team learning, which positively affected perceived team performance. We found no evidence for transformative intra-team learning as a mediator between team efficacy and student evaluation. Thus, similar to task interdependence, only the relationship between team efficacy and perceived team performance was mediated, by only adaptive intra-team learning.

Table 2 Standardized indirect and total effects of team efficacy and task interdependence on team effectiveness

\begin{tabular}{|c|c|c|c|c|c|c|}
\hline & \multicolumn{3}{|c|}{ Team performance } & \multicolumn{3}{|c|}{ Student evaluation } \\
\hline & Direct & Indirect & Total & Direct & Indirect & Total \\
\hline Team efficacy & $.68 * *$ & & $.71 * *$ & -.05 & & .07 \\
\hline Through adaptive intra-team learning & & $.13 * *$ & & & -.01 & \\
\hline Through transformative intra-team learning & & -.09 & & & .13 & \\
\hline Task interdependence & .01 & & .08 & -.12 & & -.03 \\
\hline Through adaptive intra-team learning & & $.13^{*}$ & & & -.01 & \\
\hline Through transformative intra-team learning & & -.07 & & & .10 & \\
\hline
\end{tabular}

$* p<.05, * * p<.01$ 


\section{Discussion}

The aim of this study was to provide more insight in the interrelationship between intraand inter-team learning and their influence on team performance. Moreover, by incorporating both a direct and an interactive effect of intra- and inter-team learning, we set out to further our knowledge on the added value of inter-team learning to intra-team learning. In a field study among 108 university teacher teams, we tested a path model including cultural and structural input factors, adaptive and transformative intra-team learning, inter-team learning, and perceived team performance and student evaluations.

\section{Summary of Findings and Implications}

Supporting Hypothesis 1, the results showed that both adaptive and transformative intra-team learning are important contributors to team performance. Interestingly, adaptive and transformative intra-team learning had a distinct effect on the performance indicators. Adaptive intra-team learning positively affected self-rated, and not studentrated, team performance. The opposite was true for transformative intra-team learning: it positively affected student-rated, but not self-rated, team performance. This divergence in results between self- and externally rated performance is a common phenomenon in educational and organizational research (Van Woerkom and Croon 2009; Wagner et al. 2016). Specifically, in a university teaching context, teachers and students are likely to rely on different sources for rating the quality of courses, and have different perceptions of educational performance. The fact that teams themselves only experience adaptive intra-team learning as a positive contributor to team performance may not be surprising considering that engaging in transformative, more complex team interactions, such as discussing divergent perspectives, may not always lead to comfortable group dynamics. The fact that for student-rated team performance, solely transformative intra-team learning is beneficial, however, indicates that teams do bear the fruits from engaging in these complex integrative interactions, as it likely makes the curriculum more engaging and innovative. As such, our results stress that while adaptive intra-team learning may be beneficial for self-perceived team effectiveness, transformative intra-team learning processes seem crucial for coming to well-considered and innovative team products that are highly valued by external parties (Akkerman and Bakker 2011; Sessa et al. 2011).

Our results on Hypothesis 2 showed that inter-team learning can be both of added value and an impediment to the relationship between intra-team learning and studentrated team performance. Specifically, our results showed that while inter-team learning added value in combination with high adaptive intra-team learning, it hurts performance when combined with high transformative intra-team learning. This implies that the facilitating versus impeding contribution of inter-team learning not only depends on the task environment (Bresman 2013), but also on the level of intra-team learning. Teams that engage in adaptive intra-team learning proceed from agreement and work on refining solutions and accumulating existing knowledge (Ellström 2001; London and Sessa 2007). They benefit from inter-team learning because the team members likely have a shared conception of why and how to use external input and thus easily process the retrieved knowledge. Transformative intra-team learning, on the other hand, 
requires high cognitive effort and is more time-consuming (Sessa et al. 2011). When teams engage highly in transformative intra-team learning and are simultaneously confronted with a large amount of additional external knowledge, they may experience too much diversity and cognitive overload. As a result, their search for consensus and integration can become an endless negotiation, resulting in a deadlock and suffering team performance (Choi 2002). All in all, a strong adaptive team learning strategy seems to serve as a basic precondition in order for a team to profit from transformative team learning and from inter-team learning.

Regarding the input factors (Hypothesis 3 and Hypothesis 4), we found that teams that experience high team efficacy and task interdependence indicate higher levels of adaptive and transformative intra-team learning. Moreover, both team efficacy and task interdependence positively affected perceived team performance via increased adaptive intra-team learning. These findings replicate and confirm prior research demonstrating the importance of team efficacy and interdependence for achieving high team performance (Gully et al. 2002; Lemieux-Charles and McGuire 2006; LePine et al. 2008). Moreover, they underline how in a traditionally individualistic task-context, perceived efficacy and task interdependence among university teachers may form the 'social glue' to build social networks within teams (Moolenaar et al. 2012).

The current study has yielded two important implications for future team learning research. First, our findings indicate that the moderating effect of interteam learning on the relationship between intra-team learning and team performance can be explained from the framework of adaptive and transformative learning. In the current study, we took a unidimensional approach to inter-team learning, but we do want to stipulate to the possibility of applying the same distinction between adaptive and transformative learning to inter-team learning as well. Where adaptive inter-team learning may then consist of rather onesided information seeking activities that yield knowledge that directly fits a team's existing shared mental model, transformative inter-team learning may be a more reciprocal process in which a team and an external party mutually discuss and integrate knowledge. For example, as Bresman (2010) already showed that the moderating effect of inter-team learning differs when approaching competing versus cooperative external parties, adopting a multidimensional conceptualization of both intra- and inter-team learning in future studies might provide us with even more fine-grained insights in the relationship between team learning and team performance.

Second, research on collaborative learning is conducted from different paradigms, varying from a completely cognitive view on team learning in which teams are seen as information-processing units that acquire knowledge (e.g. Van Woerkom and Croon 2009), to a completely participatory view in which learning is seen as completely situated in a team's practices (e.g. Van Waes et al. 2015). Our study was conducted from a socio-cognitive perspective (Van den Bossche et al. 2011), in which social interaction serves the creation of knowledge (Paavola et al. 2004), specifically by building a shared mental model. In order to maintain and proceed conceptual clarity on team learning constructs, and for future researchers to choose an appropriate methodology for studying team learning, we stress that it is of great importance for other scholars to explicitly address the paradigm that guides their research. 


\section{Limitations and Future Perspectives}

Based on the insights and limitations of the current study, we propose several directions for future research.

First, in this study, we viewed team learning as a dynamic construct, emerging from interactions between people (Paavola et al. 2004). As a result, team learning processes are subject to continuous change, both on a micro-level (e.g. within one conversation) and on a more macro-level (e.g. within and over multiple design cycles). However, the cross-sectional nature of the current study and the adoption of the IPO-framework (Ilgen et al. 2005; Kozlowski 2015), restrained us from drawing causal conclusions and building knowledge on the temporal aspects of team learning. We therefore want to side with the growing call for adopting more longitudinal methods (Kozlowski 2015; Mohammed et al. 2015), which are necessary for further exploration of when exactly the combination of intra- and inter-team learning adds to team performance. For example, teams may first need to focus their efforts on intra-team learning in order to build within-team efficacy and interdependence, before gathering knowledge from external parties. Inter-team learning can thus form an impediment at one point in time, while adding value at a later moment.

Second, survey studies are prone to common method and social desirability biases (Krumpal 2013; Podsakoff et al. 2003). To overcome these potential problems, we included an externally rated measure of team performance (i.e., student evaluations) and we included moderators in our SEM model: participants' responses cannot be biased in terms of interaction terms (Chang et al. 2010). Although we found no evidence of the presence of common method bias in our study (Podsakoff et al. 2003), we recommend for future studies to use multiple methods. Besides for triangulation purposes, using a mixed method design could also extend the focus of the current study on the quantity of team learning to how the quality and content of team learning determine whether teams yield higher performance (Van der Haar et al. 2013b; Zoethout et al. 2017).

Third, our hypothesis for a complementing interaction of intra- and inter-team learning was based on a conceptual analysis of the task environment in our specific study context (Bresman and Zellmer-Bruhn 2013). The complex and innovative aspects of the teacher teams' task in the current study context are not generalizable to all other team learning contexts. From a socio-cognitive perspective on team learning, however, it is crucial to take these context-specific elements into account when hypothesizing on the relationship between team learning and team performance relationship. For strengthening the knowledge base on effects of team learning across multiple contexts, conducting a metaanalysis including elements of the task environment as moderating variables (e.g. working on a routine task versus an innovative task) would be highly valuable.

Fourth, the current conceptual model could be extended in future studies, by including additional input factors that are likely to affect team learning and team performance, such as team leadership (Ortega et al. 2014; Raes et al. 2013; Siewiorek et al. 2013) and psychological safety (Edmondson 1999; Ortega et al. 2014). As our sample size was relatively low for SEM, we strived for a parsimonious model, and only included the most important input factors for our specific study context (Van der Haar et al. 2013a), which we deemed task interdependence and team efficacy. We advise future researchers to gather data from a larger sample of teams. 
Finally, though team learning can be considered especially important in newly composed teams that have yet to start building a shared mental model (Edmondson 1999), a substantial part of our sample (20 teams, 18.5\%) did not engage in any face-toface team discussions at all. In our study, we were only able to include the teams that did engage to some extent in team learning processes during meetings, as our team learning items referred to learning from each other in a face-to-face social context (Van den Bossche et al. 2011). Although collaboration in research is very common in academia (Van der Rijst 2009), collaboration within teaching is rather new (Gast et al. 2017). In order to provide students with the multidisciplinary and innovative skills needed for their future jobs, university teachers will more and more need to collaborate (Akbari et al. 2016). Therefore, it would be of high interest for future studies in the university teaching context, to focus also on how to motivate teacher teams to take part in team learning through face-to-face discussion, in order to develop shared educational practices.

\section{Conclusion}

All in all, our findings indicate that intra-team and inter-team learning are both a constructive and destructive combination in relation to team performance. Most importantly, the level of intra-team learning (adaptive versus transformative) seems to explain whether inter-team learning is of added value or an impediment to intra-team learning. On the one hand, teams perceived to perform well when they shared and refined existing practices, and when these activities were combined with learning from externals it also impacted positively on student-rated team performance. On the other hand, efforts to integrate ideas and perspectives directly led to high student-rated team performance. However, combined with high inter-team learning this positive effect was cancelled out. Concluding, effects of intra- and inter-team learning on team effectiveness can only be understood from the framework of adaptive and transformative learning.

\section{Appendix 1}

\section{Survey items and origin}

All items were measured on a 5-point scale, ranging from $1=$ completely disagree to $5=$ completely agree.

\section{Intra-team Learning}

Adaptive intra-team learning (Van den Bossche et al. 2011; Van Offenbeek 2001)

1. Team members elaborate on each other's information and ideas.

2. In this team, background information is spread among all team members. 
3. In this team, we share all relevant information and ideas we have.

4. Team members are listening carefully to each other.

5. Members of this team ask each other for help and advice during the module work.

6. If something is unclear, we ask each other questions.

7. Team members draw conclusions from the ideas that are discussed in the team. Removed.

8. Information from team members is complemented with information from other team members. Removed.

Transformative intra-team learning (Van den Bossche et al. 2011; Van Offenbeek 2001)

9. Opinions and ideas of team members are verified by asking each other critical questions.

10. In this team we ask critical questions when someone tells something new.

11. When different possible decisions about the module come forward in a discussion, team members ask additional questions.

12. In a discussion, our team views a topic from different angles and brings those forward.

13. This team tends to handle differences in opinions by addressing them directly.

14. When a team member has a divergent opinion during a discussion, he or she still says so.

15. Members of this team ask proper questions in order to see through each other's information. Removed.

16. When a team member gives an explanation, other team members come up with complementary explanations.

17. Team members who formulate an explanation concerning the module ask in between times whether their explanation is right.

18. Comments and ideas are acted upon. Removed.

\section{Inter-team Learning - Based on Wong (2004) and Bresman (2010)}

1. This team invites persons from outside the team to join the discussion about how we can avoid pitfalls.

2. Members of this team talk with persons from outside the team about mistakes that have been made, in order to improve the working process.

3. This team reflects with persons from outside the team on what has worked for them in their module.

4. This team evaluates its work together with persons from outside the team.

5. In this team, we look for persons from outside the team whom we can ask for advice about designing our module.

6. Members of this team review the work of persons from outside the team, in order to learn lessons for our own module.

7. This team is looking for ideas and expertise from persons from outside the team. 


\section{Performance Measures}

Perceived team performance - Based on Van Woerkom and Croon (2009) and Zellmer-Bruhn and Gibson (2006)

1. In this team, we perform well.

2. In this team, we spend our time well.

3. This team meets its expectations.

4. This team accomplishes its objectives.

5. In this team, we work efficiently.

\section{Student evaluation (retrieved from the institutional student survey)}

1. In general, the teaching and learning in the module were a good fit for how I learn. Consider for instance: thinking things through before taking action; learning in cooperation; applying theory in reality.

2. The module was well organised. Consider for instance: clear assignments, clear rules for assessments

3. The module was logically put together. Consider for instance: parts of the module were connected well; good sequence of module parts

4. I have learned a lot from the teachers, tutors, teaching assistants, etc.

5. The tests were suitable to determine whether I'd learned sufficiently

6. As a whole, I learned a lot in the module

\section{Structural and cultural input factors}

\section{Task interdependence (Oude Groote Beverborg et al. 2015)}

1. In order for this team to carry out our tasks, we need information from each other.

2. In order to do our job well, we have to collaboratie within our team.

3. The work of one team member influences the execution of tasks of other members of this team.

4. In order to do our job well, we have to gear our tasks to on another.

\section{Team efficacy (Moolenaar et al. 2012)}

1. In our team, teachers sometimes give up, when developing a part of the module does not work out. (Reversed)

2. In our team, teachers are able to design a module that challenges students to learn.

3. In our team, teachers really believe that we can teach every student something in our module.

4. In our team, we can design a module that motivates students.

5. In our team, we can design a module that is able to get through to difficult students. 


\section{Appendix 2}

Table 3 Exploratory factor analysis loadings

\begin{tabular}{|c|c|c|c|}
\hline \multirow[t]{2}{*}{ Item } & \multicolumn{3}{|l|}{ Factor loadings } \\
\hline & $\begin{array}{l}\text { Transformative } \\
\text { intra-team learning }\end{array}$ & Inter-team learning & $\begin{array}{l}\text { Adaptive intra-team } \\
\text { learning }\end{array}$ \\
\hline Intra-team learning 9 & .80 & .01 & -.03 \\
\hline Intra-team learning 10 & .80 & -.02 & -.03 \\
\hline Intra-team learning 11 & .77 & .03 & -.01 \\
\hline Intra-team learning 12 & .70 & .09 & .05 \\
\hline Intra-team learning 13 & .61 & .07 & .06 \\
\hline Intra-team learning 14 & .57 & .02 & .13 \\
\hline Intra-team learning 15 & .57 & -.07 & .32 \\
\hline Intra-team learning 16 & .56 & .03 & .07 \\
\hline Intra-team learning 17 & .42 & .12 & .13 \\
\hline Intra-team learning 18 & .41 & .07 & .35 \\
\hline Inter-team learning 1 & -.04 & .74 & .02 \\
\hline Inter-team learning 2 & .16 & .71 & -.16 \\
\hline Inter-team learning 3 & .13 & .71 & -.07 \\
\hline Inter-team learning 4 & .12 & .68 & -.17 \\
\hline Inter-team learning 5 & -.14 & .68 & -.17 \\
\hline Inter-team learning 6 & -.11 & .63 & .21 \\
\hline Inter-team learning 7 & -.06 & .56 & .22 \\
\hline Intra-team learning 1 & -.02 & .07 & .78 \\
\hline Intra-team learning 2 & .04 & -.05 & .67 \\
\hline Intra-team learning 3 & .13 & .00 & .67 \\
\hline Intra-team learning 4 & .11 & .00 & .55 \\
\hline Intra-team learning 5 & .14 & .16 & .53 \\
\hline Intra-team learning 6 & .29 & -.05 & .46 \\
\hline Intra-team learning 7 & .42 & -.01 & .46 \\
\hline Intra-team learning 8 & .30 & .17 & .45 \\
\hline
\end{tabular}

Bold factor loadings meet the $>.32$ criterion for item retention (Worthington and Whittaker 2006)

Open Access This article is distributed under the terms of the Creative Commons Attribution 4.0 International License (http://creativecommons.org/licenses/by/4.0/), which permits unrestricted use, distribution, and reproduction in any medium, provided you give appropriate credit to the original author(s) and the source, provide a link to the Creative Commons license, and indicate if changes were made. 


\section{References}

Akbari, M., Kashani, S. H., \& Hooshmand Chaijani, M. (2016). Sharing, caring, and responsibility in higher education teams. Small Group Research, 47(5), 542-568. https://doi.org/10.1177/1046496416667609

Akkerman, S. F., \& Bakker, A. (2011). Boundary crossing and boundary objects. Review of Educational Research, 81(2), 132-169. https://doi.org/10.3102/0034654311404435

Akkerman, S. F., Van den Bossche, P., Admiraal, W., Gijselaers, W., Segers, M., Simons, R.-J., \& Kirschner, P. (2007). Reconsidering group cognition: From conceptual confusion to a boundary area between cognitive and socio-cultural perspectives? Educational Research Review, 2(1), 39-63. https://doi.org/10.1016/j. edurev.2007.02.001

Ancona, D. G., \& Caldwell, D. F. (1992). Bridging the boundary: External activity and performance in organizational teams. Administrative Science Quarterly, 37(4), 634-665. https://doi.org/10.2307/2393475

Antoni, C., \& Hertel, G. (2009). Team processes, their antecedents and consequences: Implications for different types of teamwork. European Journal of Work and Organizational Psychology, 18(3), 253266. https://doi.org/10.1080/13594320802095502

Bandura, A. (1993). Perceived self-efficacy in cognitive development and functioning. Educational Psychologist, 28(2), 117-148. https://doi.org/10.1207/s15326985ep2802 3

Barile, S., Franco, G., Nota, G., \& Saviano, M. (2012). Structure and dynamics of a "T-shaped” knowledge: From individuals to cooperating communities of practice. Service Science, 4(2), 161-180. https://doi.org/10.1287/serv.1120.0014

Bliese, P. D. (2000). Within-group agreement, non-independence, and reliability: Implications for data aggregation and analysis. In K. J. Klein \& S. W. J. Kozlowski (Eds.), Multilevel theory, research, and methods in organizations: Foundations, extensions, and new directions (pp. 349-381). San Francisco: Jossey-Bass.

Bresman, H. (2010). External learning activities and team performance: A multimethod field study. Organization Science, 21(1), 81-96. https://doi.org/10.1287/orsc.1080.0413

Bresman, H. (2013). Changing routines: A process model of vicarious group learning in Pharmaceutical R\&D. Academy of Management Journal, 56(1), 35-61. https://doi.org/10.5465/amj.2010.0725

Bresman, H., \& Zellmer-Bruhn, M. (2013). The structural context of team learning: Effects of organizational and team structure on internal and external learning. Organization Science, 24(4), 11201139. https://doi.org/10.1287/orsc. 1120.0783

Chan, C. C., Lim, L., \& Keasberry, S. K. (2003). Examining the linkages between team learning behaviors and team performance. The Learning Organization, 10(4), 228-236. https://doi.org/10.1108 /09696470310476990

Chang, S.-J., van Witteloostuijn, A., \& Eden, L. (2010). From the editors: Common method variance in international business research. Journal of International Business Studies, 41(2), 178-184. https://doi.org/10.1057/jibs.2009.88

Choi, J. N. (2002). External activities and team effectiveness: Review and theoretical development. Small Group Research, 33(2), 181-208. https://doi.org/10.1177/104649640203300202

De Dreu, C. K. W., \& Weingart, L. R. (2003). Task versus relationship conflict, team performance, and team member satisfaction: A meta-analysis. Journal of Applied Psychology, 88(4), 741-749. https://doi.org/10.1037/0021-9010.88.4.741

De Groot, E., Jaarsma, D., Endedijk, M., Mainhard, T., Lam, I., Simons, R.-J., \& Beukelen, P. v. (2012). Critically reflective work behavior of health care professionals. Journal of Continuing Education in the Health Professions, 32(1), 48-57. https://doi.org/10.1002/chp.21122

De Wit, F. R. C., Greer, L. L., \& Jehn, K. A. (2012). The paradox of intragroup conflict: A meta-analysis. Journal of Applied Psychology, 97(2), 360-390. https://doi.org/10.1037/a0024844

Decuyper, S., Dochy, F., \& Van den Bossche, P. (2010). Grasping the dynamic complexity of team learning: An integrative model for effective team learning in organisations. Educational Research Review, 5(2), 111-133. https://doi.org/10.1016/j.edurev.2010.02.002

Edmondson, A. C. (1999). Psychological safety and learning behavior in work teams. Administrative Science Quarterly, 44(2), 350-383. https://doi.org/10.2307/2666999

Ellström, P.-E. (2001). Integrating learning and work: Problems and prospects. Human Resource Development Quarterly, 12(4), 421-435. https://doi.org/10.1002/hrdq.1006

Engeström, Y., Engeström, R., \& Kärkkäinen, M. (1995). Polycontextuality and boundary crossing in expert cognition: Learning and problem solving in complex work activities. Learning and Instruction, 5(4), 319336. https://doi.org/10.1016/0959-4752(95)00021-6 
Gast, I., Schildkamp, K., \& van der Veen, J. T. (2017). Team-based professional development interventions in higher education: A systematic review. Review of Educational Research, 87(4), 736-767. https://doi.org/10.3102/0034654317704306

Gully, S. M., Incalcaterra, K. A., Joshi, A., \& Beaubien, J. M. (2002). A meta-analysis of team-efficacy, potency, and performance: Interdependence and level of analysis as moderators of observed relationships. Journal of Applied Psychology, 87(5), 819-832. https://doi.org/10.1037/0021-9010.87.5.819

Hayes, A. F., Montoya, A. K., \& Rockwood, N. J. (2017). The analysis of mechanisms and their contingencies: PROCESS versus structural equation modeling. Australasian Marketing Journal (AMJ), 25(1), 7681. https://doi.org/10.1016/j.ausmj.2017.02.001

Hox, J. J., \& Bechger, T. M. (1998). An introduction to structural equation modeling. Family Science Review, 11(4), 354-373.

Hu, L. t., \& Bentler, P. M. (1999). Cutoff criteria for fit indexes in covariance structure analysis: Conventional criteria versus new alternatives. Structural Equation Modeling: A Multidisciplinary Journal, 6(1), 1-55. https://doi.org/10.1080/10705519909540118

Hülsheger, U. R., Anderson, N., \& Salgado, J. F. (2009). Team-level predictors of innovation at work: A comprehensive meta-analysis spanning three decades of research. Journal of Applied Psychology, 94(5), 1128-1145. https://doi.org/10.1037/a0015978

Ilgen, D. R., Hollenbeck, J. R., Johnson, M., \& Jundt, D. (2005). Teams in organizations: From input-processoutput models to IMOI models. Annual Review of Psychology, 56(1), 517-543. https://doi.org/10.1146 /annurev.psych.56.091103.070250

Jehn, K. A., \& Rupert, J. (2008). Group fault lines and team learning: How to benefit from different perspectives. Work group learning: Understanding, improving, \& assessing how groups learn in organizations, Lawrence Erlbaum Associates, New York, NY, 119-147.

Kasl, E., Marsick, V. J., \& Dechant, K. (1997). Teams as learners: A research-based model of team learning. The Journal of Applied Behavioral Science, 33(2), 227-246. https://doi.org/10.1177/0021886397332010

Kerosuo, H., \& Engeström, Y. (2003). Boundary crossing and learning in creation of new work practice. Journal of Workplace Learning, 15(7/8), 345-351. https://doi.org/10.1108/13665620310504837

Kline, R. B. (2011). Principles and practice of structural equation modeling. New York: The Guilford Press.

Knapp, R. (2010). Collective (team) learning process models: A conceptual review. Human Resource Development Review, 9(3), 285-299. https://doi.org/10.1177/1534484310371449

Koeslag-Kreunen, M. G. M., Van der Klink, M. R., Van den Bossche, P., \& Gijselaers, W. H. (2017). Leadership for team learning: The case of university teacher teams. Higher Education. https://doi.org/10.1007/s10734-017-0126-0

Kostopoulos, K. C., \& Bozionelos, N. (2011). Team exploratory and exploitative learning: Psychological safety, task conflict, and team performance. Group and Organization Management, 36(3), 385-415. https://doi.org/10.1177/1059601111405985

Kozlowski, S. W. J. (2015). Advancing research on team process dynamics: Theoretical, methodological, and measurement considerations. Organizational Psychology Review, 5(4), 270-299. https://doi.org/10.1177 $/ 2041386614533586$

Kozlowski, S. W. J., \& Bell, B. S. (2013). Work groups and teams in organizations: Review update. In N. Schmitt \& S. Highhouse (Eds.), Handbook of psychology: Vol. 12. Industrial and organizational psychology. Hoboken: Wiley.

Kozlowski, S. W. J., \& Ilgen, D. R. (2006). Enhancing the effectiveness of work groups and teams. Psychological Science in the Public Interest, 7(3), 77-124. https://doi.org/10.1111/j.15291006.2006.00030.x

Kozlowski, S. W. J., Chao, G. T., Grand, J. A., Braun, M. T., \& Kuljanin, G. (2013). Advancing multilevel research design: Capturing the dynamics of emergence. Organizational Research Methods. https://doi.org/10.1177/1094428113493119

Krumpal, I. (2013). Determinants of social desirability bias in sensitive surveys: A literature review. Quality \& Quantity, 47(4), 2025-2047. https://doi.org/10.1007/s11135-011-9640-9

Kyndt, E., \& Onghena, P. (2014). The integration of work and learning: Tackling the complexity with structural equation modelling. In C. Harteis, A. Rausch, \& J. Seifried (Eds.), Discourses on professional learning (Vol. 9, pp. 255-291). Netherlands: Springer.

LeBreton, J. M., \& Senter, J. L. (2007). Answers to 20 questions about interrater reliability and interrater agreement. Organizational Research Methods. https://doi.org/10.1177/1094428106296642

Lemieux-Charles, L., \& McGuire, W. L. (2006). What do we know about health care team effectiveness? A review of the literature. Medical Care Research and Review, 63(3), 263-300. https://doi.org/10.1177 $/ 1077558706287003$ 
LePine, J. A., Piccolo, R. F., Jackson, C. L., Mathieu, J. E., \& Saul, J. R. (2008). A meta-analysis of teamwork processes: Tests of a multidimensional model and relationships with team effectiveness criteria. Personnel Psychology, 61(2), 273-307. https://doi.org/10.1111/j.1744-6570.2008.00114.x

London, M., \& Sessa, V. I. (2007). The development of group interaction patterns: How groups become adaptive, generative, and transformative learners. Human Resource Development Review, 6(4), 353-376. https://doi.org/10.1177/1534484307307549

MacKinnon, D. P., Lockwood, C. M., \& Williams, J. (2004). Confidence limits for the indirect effect: Distribution of the product and resampling methods. Multivariate Behavioral Research, 39(1), 99-128. https://doi.org/10.1207/s15327906mbr3901_4

Marrone, J. A. (2010). Team boundary spanning: A multilevel review of past research and proposals for the future. Journal of Management, 36(4), 911-940. https://doi.org/10.1177/0149206309353945

Marrone, J. A., Tesluk, P. E., \& Carson, J. B. (2007). A multilevel investigation of antecedents and consequences of team member boundary-spanning behavior. Academy of Management Journal, 50(6), 1423-1439. https://doi.org/10.5465/amj.2007.28225967

Mesmer-Magnus, J. R., \& DeChurch, L. A. (2009). Information sharing and team performance: A metaanalysis. Journal of Applied Psychology, 94(2), 535-546. https://doi.org/10.1037/a0013773

Mohammed, S., Hamilton, K., Tesler, R., Mancuso, V., \& McNeese, M. (2015). Time for temporal team mental models: Expanding beyond "what" and "how" to incorporate "when". European Journal of Work and Organizational Psychology, 24(5), 693-709. https://doi.org/10.1080 /1359432x.2015.1024664

Moolenaar, N. M., Sleegers, P. J. C., \& Daly, A. J. (2012). Teaming up: Linking collaboration networks, collective efficacy, and student achievement. Teaching and Teacher Education, 28(2), 251-262. https://doi.org/10.1016/j.tate.2011.10.001

Nevitt, J., \& Hancock, G. R. (2001). Performance of bootstrapping approaches to model test statistics and parameter standard error estimation in structural equation modeling. Structural Equation Modeling: A Multidisciplinary Journal, 8(3), 353-377. https://doi.org/10.1207 /S15328007SEM0803 2

Ortega, A., Van den Bossche, P., Sánchez-Manzanares, M., Rico, R., \& Gil, F. (2014). The influence of change-oriented leadership and psychological safety on team learning in healthcare teams. Journal of Business and Psychology, 29(2), 311-321. https://doi.org/10.1007/s10869013-9315-8

Oude Groote Beverborg, A., Sleegers, P. J. C., \& van Veen, K. (2015). Fostering teacher learning in VET colleges: Do leadership and teamwork matter? Teaching and Teacher Education, 48, 22-33. https://doi. org/10.1016/j.tate.2015.01.015

Paavola, S., \& Hakkarainen, K. (2005). The knowledge creation metaphor - An emergent epistemological approach to learning. Science \& Education, 14(6), 535-557. https://doi.org/10.1007/s11191-004-5157-0

Paavola, S., Lipponen, L., \& Hakkarainen, K. (2004). Models of innovative knowledge communities and three metaphors of learning. Review of Educational Research, 74(4), 557-576. https://doi.org/10.3102 $/ 00346543074004557$

Pek, J., \& Hoyle, R. H. (2016). On the (in)validity of tests of simple mediation: Threats and solutions. Social and Personality Psychology Compass, 10(3), 150-163. https://doi.org/10.1111/spc3.12237

Podsakoff, P. M., MacKenzie, S. B., Lee, J.-Y., \& Podsakoff, N. P. (2003). Common method biases in behavioral research: A critical review of the literature and recommended remedies. Journal of Applied Psychology, 88(5), 879-903. https://doi.org/10.1037/0021-9010.88.5.879

Raes, E., Decuyper, S., Lismont, B., den Bossche, P., Kyndt, E., Demeyere, S., \& Dochy, F. (2013). Facilitating team learning through transformational leadership. Instructional Science, 41(2), 287-305. https://doi.org/10.1007/s11251-012-9228-3

Rosseel, Y. (2012). Lavaan: An R package for structural equation modeling. Journal of Statistical Software, 48(2), 1-36.

Schippers, M. C., Homan, A. C., \& van Knippenberg, D. (2013). To reflect or not to reflect: Prior team performance as a boundary condition of the effects of reflexivity on learning and final team performance. Journal of Organizational Behavior, 34(1), 6-23. https://doi.org/10.1002/job.1784

Schmitt, T. A. (2011). Current methodological considerations in exploratory and confirmatory factor analysis. Journal of Psychoeducational Assessment, 29(4), 304-321. https://doi.org/10.1177 $/ 0734282911406653$

Scott, P. (2000). Globalisation and higher education: Challenges for the 21st century. Journal of Studies in International Education, 4(1), 3-10. https://doi.org/10.1177/102831530000400102 
Sessa, V. I., London, M., Pingor, C., Gullu, B., \& Patel, J. (2011). Adaptive, generative, and transformative learning in project teams. Team Performance Management: An International Journal, 17(3/4), 146-167. https://doi.org/10.1108/13527591111143691

Siewiorek, A., Gegenfurtner, A., Lainema, T., Saarinen, E., \& Lehtinen, E. (2013). The effects of computersimulation game training on participants' opinions on leadership styles. British Journal of Educational Technology, 44(6), 1012-1035. https://doi.org/10.1111/bjet.12084

Silberstang, J., \& London, M. (2009). How groups learn:The role of communication patterns, cue recognition, context facility, and cultural intelligence. Human Resource Development Review, 8(3), 327-349. https://doi.org/10.1177/1534484309337300

Stalmeijer, R. E., Gijselaers, W. H., Wolfhagen, I. H. A. P., Harendza, S., \& Scherpbier, A. J. J. A. (2007). How interdisciplinary teams can create multi-disciplinary education: The interplay between team processes and educational quality. Medical Education, 41(11), 1059-1066. https://doi.org/10.1111/j.13652923.2007.02898.x

Timmermans, O., Van Linge, R., Van Petegem, P., Van Rompaey, B., \& Denekens, J. (2012). Team learning and innovation in nursing, a review of the literature. Nurse Education Today, 32(1), 65-70. https://doi.org/10.1016/j.nedt.2011.07.006

Turner, J. R., Chen, Q., \& Danks, S. (2014). Team shared cognitive constructs: A meta-analysis exploring the effects of shared cognitive constructs on team performance. Performance Improvement Quarterly, 27(1), 83-117. https://doi.org/10.1002/piq.21163

Van den Bossche, P., Gijselaers, W. H., Segers, M., \& Kirschner, P. A. (2006). Social and cognitive factors driving teamwork in collaborative learning environments: Team learning beliefs and behaviors. Small Group Research, 37(5), 490-521. https://doi.org/10.1177/1046496406292938

Van den Bossche, P., Gijselaers, W., Segers, M., Woltjer, G., \& Kirschner, P. (2011). Team learning: Building shared mental models. Instructional Science, 39(3), 283-301. https://doi.org/10.1007/s11251-010-9128-3

Van der Haar, S., Segers, M., \& Jehn, K. A. (2013a). Towards a contextualized model of team learning processes and outcomes. Educational Research Review, 10, 1-12. https://doi.org/10.1016/j. edurev.2013.04.001

Van der Haar, S., Wijenbergh, B., Van den Bossche, P., \& Segers, M. (2013b). Team learning behavior: A study in the setting of command and control teams. München: Paper presented at the EARLI.

Van der Rijst, R. M. (2009). The research-teaching nexus in the sciences: Scientific research dispositions and teaching practice: ICLON, Leiden University Graduate School of Teaching.

Van der Vegt, G. S., Van de Vliert, E., \& Oosterhof, A. (2003). Informational dissimilarity and organizational citizenship behavior: The role of Intrateam interdependence and team identification. The Academy of Management Journal, 46(6), 715-727. https://doi.org/10.2307/30040663

Van Offenbeek, M. (2001). Processes and outcomes of team learning. European Journal of Work and Organizational Psychology, 10(3), 303-317. https://doi.org/10.1080/13594320143000690

Van Waes, S., Van den Bossche, P., Moolenaar, N. M., De Maeyer, S., \& Van Petegem, P. (2015). Know-who? Linking faculty's networks to stages of instructional development. Higher Education, 70(5), 807-826. https://doi.org/10.1007/s10734-015-9868-8

Van Woerkom, M., \& Croon, M. (2009). The relationships between team learning activities and team performance. Personnel Review, 38(5), 560-577. https://doi.org/10.1108/00483480910978054

Veestraeten, M., Kyndt, E., \& Dochy, F. (2013). Investigating team learning in a military context. Vocations and Learning, 7(1), 75-100. https://doi.org/10.1007/s12186-013-9107-3

Visschers-Pleijers, A. J. S. F., Dolmans, D. H. J. M., Wolfhagen, I. H. A. P., \& van der Vleuten, C. P. M. (2005). Development and validation of a questionnaire to identify learning-oriented group interactions in PBL. Medical Teacher, 27(4), 375-381. https://doi.org/10.1080/01421590500046395

Wagner, W., Göllner, R., Werth, S., Voss, T., Schmitz, B., \& Trautwein, U. (2016). Student and teacher ratings of instructional quality: Consistency of ratings over time, agreement, and predictive power. Journal of Educational Psychology, 108(5), 705.

Wijnia, L., Kunst, E. M., van Woerkom, M., \& Poell, R. F. (2016). Team learning and its association with the implementation of competence-based education. Teaching and Teacher Education, 56, 115-126. https://doi.org/10.1016/j.tate.2016.02.006

Wilson, J. M., Goodman, P. S., \& Cronin, M. A. (2007). Group learning. Academy of Management Review, 32(4), 1041-1059. https://doi.org/10.5465/amr.2007.26585724

Wong, S. (2004). Distal and local group learning: Performance trade-offs and tensions. Organization Science, 15(6), 645-656. https://doi.org/10.2307/30034767 
Worthington, R. L., \& Whittaker, T. A. (2006). Scale development research: A content analysis and recommendations for best practices. The Counseling Psychologist, 34(6), 806-838. https://doi.org/10.1177/0011000006288127

Zellmer-Bruhn, M. (2003). Interruptive events and team knowledge acquisition. Management Science, 49(4), 514-528. https://doi.org/10.1287/mnsc.49.4.514.14423

Zellmer-Bruhn, M., \& Gibson, C. (2006). Multinational organization context: Implications for team learning and performance. Academy of Management Journal, 49(3), 501-518. https://doi.org/10.5465 /amj.2006.21794668

Zoethout, H., Wesselink, R., Runhaar, P., \& Mulder, M. (2017). Using Transactivity to understand emergence of team learning. Small Group Research, 1-25. https://doi.org/10.1177/1046496417691614

Rike Bron is PhD student at the Department of Educational Sciences, University of Twente. Her main research interest is individual, team, and organizational learning at the workplace. Her current research project focusses on how intra- and inter-team learning in university teacher teams leads to the development of a shared mental model and subsequent team effectiveness.

Maaike D. Endedijk is Associate Professor in the field of professional learning at the Department of Educational Sciences, University of Twente. Her main research interest is self-directed learning at the workplace, both on the individual and team level. Her current research projects take place in the health and technical sector and aim to better understand the dynamics of these self-directed learning processes and unravel important predictors and outcomes.

Ruth van Veelen is Post Doctoral researcher at the Department of Social-, Health, and Organizational Psychology. Her research expertise is on social identity development and diversity at the workplace. Her current research projects focus on how women in masculine working contexts (e.g., Science, Engineering) deal with gender inequality to build their careers, how age identity concerns affect intergenerational knowledge transfer, and how team diversity benefits learning and performance.

Bernard P. Veldkamp is Professor of Methodology and Statistics at the faculty of Behavioral, Management and Social Sciences, University of Twente. He is Head of Department of Research Methodology, Measurement and Data Analysis and Scientific Director of the Research Center for Examination and Certification. He specializes in research methodology and data analytics. His interests focus on optimization, text mining, and computer-based assessment. 